\title{
Turbulence and feeding behaviour affect the vertical distributions of Oithona similis and Microsetella norwegica
}

\author{
M. Maar ${ }^{1, *}$, A. W. Visser ${ }^{1}$, T. G. Nielsen ${ }^{2}$, A. Stips $^{3}{ }^{3}$ H. Saito ${ }^{4}$ \\ ${ }^{1}$ Dept. of Marine Ecology and Aquaculture, Danish Institute for Fisheries Research, Kavalergaarden 6, \\ 2920 Charlottenlund, Denmark \\ ${ }^{2}$ Dept. of Marine Ecology, National Environmental Research Institute, Frederiksborgvej 399, 4000 Roskilde, Denmark \\ ${ }^{3}$ Inland and Marine Waters Unit, CEC Joint Research Centre, TP 272, 21020 Ispra, Italy \\ ${ }^{4}$ Biological Oceanography, Tohoku National Fisheries Research Institute, Shinhama-cho 3-27-5, Shiogama 985-0001, Japan
}

\begin{abstract}
The small copepods Oithona similis and Microsetella norwegica are often numerically abundant and widely distributed, but the factors controlling their vertical distributions and role in carbon cycling are yet unknown. Here we examined the vertical distributions of copepods during spring and summer in the Skagerrak and during autumn in the North Sea with respect to different physiochemical factors including turbulent dissipation rate. The ambush feeder $O$. similis numerically dominated the copepod community; they were located in the layers with high microzooplankton abundance. M. norwegica were dominant in the Skagerrak and were observed within or just below the pycnocline; they are assumed to feed on sinking detrital aggregates. Both copepods use remote detection of either hydromechanical $(O$. similis) or chemical signals $(M$. norwegica) generated by the prey and both species migrated to deeper depths in response to elevated surface turbulence. The potential effect of turbulence on both types of feeding is theoretically shown to be negative and we suggest a turbulent dissipation rate in the range $10^{-7}$ to $10^{-6} \mathrm{~m}^{2} \mathrm{~s}^{-3}$ as a threshold triggering the observed avoidance responses.
\end{abstract}

KEY WORDS: Oithona $\cdot$ Microsetella $\cdot$ Turbulence $\cdot$ Feeding $\cdot$ Vertical distributions

Resale or republication not permitted without written consent of the publisher

\section{INTRODUCTION}

The vertical distributions of copepods have often been observed to follow the distribution of their food (Paffenhöfer 1983, Mackas et al. 1993, Richardson et al. 1998). A 'match' between copepods and their prey is important for an efficient transfer of primary productivity to higher trophic levels in the pelagic food web, while a 'mismatch' eventually leads a to greater vertical flux out of the euphotic zone. However, depth optimization by copepods is a compromise between feeding, predator avoidance, turbulence conditions and energy expenditure and the optimum depth will therefore differ between copepod species with different survival and feeding strategies (Ohman 1988). Diel verti- cal migration patterns have been observed for several copepod species and are believed to be predation avoidance mechanisms (Lampert 1993). In general, copepods stay in the productive and warm surface layers to feed during night-time and then descend to deeper layers to avoid visual predators during the day. However, the lower temperatures and food availability in the deeper layers reduces feeding, growth and fecundity (Aksnes \& Giske 1990). There seems to be a high variability in this behaviour between copepod species, life stages, and seasons (Båmstedt 2000, Irigoien et al. 2004).

Turbulence also appears to be a factor in controlling the vertical distribution of copepods (Mackas et al. 1993, Lagadeuc et al. 1997, Incze et al. 2001, Visser et 
al. 2001). Whether this is an active response to turbulence or a passive redistribution due to turbulent mixing is not fully resolved but some observations (Visser et al. 2001) and theoretical considerations (Franks 2001) suggest that in some cases it is due to active avoidance of high turbulence levels in the surface. In order to gain a mechanistic understanding of active turbulence avoidance behaviour, we tested the hypothesis that the influence of turbulence on copepod distributions depends on their feeding strategy.

Encounter rates between copepods and their prey increase with turbulence (Rothschild \& Osborn 1988) and hence increase copepod feeding during food limitation (Saiz et al. 1992). There is, however, a down side to turbulence in copepod feeding success. Very high turbulence levels for instance, can interfere with remote hydromechanical detection of prey (Kiørboe \& Saiz 1995). Likewise, copepods generating a feeding current will be affected by turbulence at levels that erode their feeding currents (Kiørboe \& Saiz 1995, Visser et al. 2001). Finally, for cruising predators using remote chemical detection of plumes behind sinking aggregates or faecal pellets, increasing turbulence disrupts the chemical plumes and decreases encounter rates (Visser \& Jackson 2004). Combining these positive and negative effects, the response of copepod feeding to turbulence may be expected to be domeshaped. In order to optimize their feeding success, copepods should locate themselves in depth strata with high food concentrations while at the same time avoiding layers where high turbulence levels interfere with their ability to detect and capture prey. The critical level of turbulence is probably species dependent. Earlier studies have found dissipation rates above $10^{-6} \mathrm{~m}^{2}$ $\mathrm{s}^{-3}$ to be critical for feeding of several ambush and suspension feeding calanoid copepods (Saiz \& Kiørboe 1995, Visser et al. 2001, Visser \& Stips 2002, Saiz et al. 2003), while it has been suggested that the cyclopoids Oithona spp. are even more sensitive to turbulence (Saiz et al. 2003). The critical turbulence level for cruising copepods using chemical detection of plumes behind sinking marine snow aggregates (Microsetella spp., Oncaea spp.) has not been investigated.

The aim of the present study is to analyze the vertical distribution of copepods, in particular the small cyclopoid Oithona similis and the small harpacticoid Microsetella norwegica, observed in the Skagerrak during 2 periods (spring 1999 and summer 2000) (Maar et al. 2002, 2004) and in the North Sea (autumn 1998) (Visser et al. 2001) in relation to different physiochemical factors. Very few studies have addressed the vertical distribution of these small non-calanoid copepod species (Lagadeuc et al. 1997, Andersen \& Nielsen 2002) and their role in the pelagic food web (Nielsen \& Sabatini 1996, Green \& Dagg 1997) even though they are highly abundant in most areas (Turner 2004). We hypothesize that the influence of turbulence on their vertical distribution in the water column should vary according to their feeding strategies. We place special emphasis on ambush feeding (O. similis) and remote chemical plume detection ( $M$. norwegica). With respect to these 2 remote detection modes, we consider theoretical relationships between clearance rate and turbulence with a view to determine mechanisms by which depth-dependent turbulence affects the success of these feeding strategies throughout the water column.

\section{MATERIALS AND METHODS}

Study areas. Sampling was conducted aboard RV 'Dana' (Danish Institute for Fisheries Research) in the Skagerrak and the northern North Sea. The Skagerrak was visited over 2 periods: a spring period (20 to 27 March 1999) and a summer period: (25 August to 3 September 2000). These 2 cruises visited the same 6 stations across the Skagerrak (Fig. 1). In the present study, we only use data from those stations where the same surface- and bottom-water masses were present during the sampling period, namely Stn $\mathrm{H}$ during spring and the transect stations (T1, T2, T3 and T4) during summer. Stn $\mathrm{H}$ was sampled intensively for $48 \mathrm{~h}$ and the transect stations were all sampled over $5 \mathrm{~d}$. Water column depth was 200 to $300 \mathrm{~m}$ at Stns $\mathrm{K}$ and $\mathrm{H}$, and 400 to $600 \mathrm{~m}$ at the transect stations. The anchor station in the North Sea $\left(1^{\circ} 0^{\prime} \mathrm{E}, 59^{\circ} 20^{\prime} \mathrm{N}\right)$ was visited in the period between 16 and 25 October 1998. The station was located away from strong currents and water column depth was $120 \mathrm{~m}$.

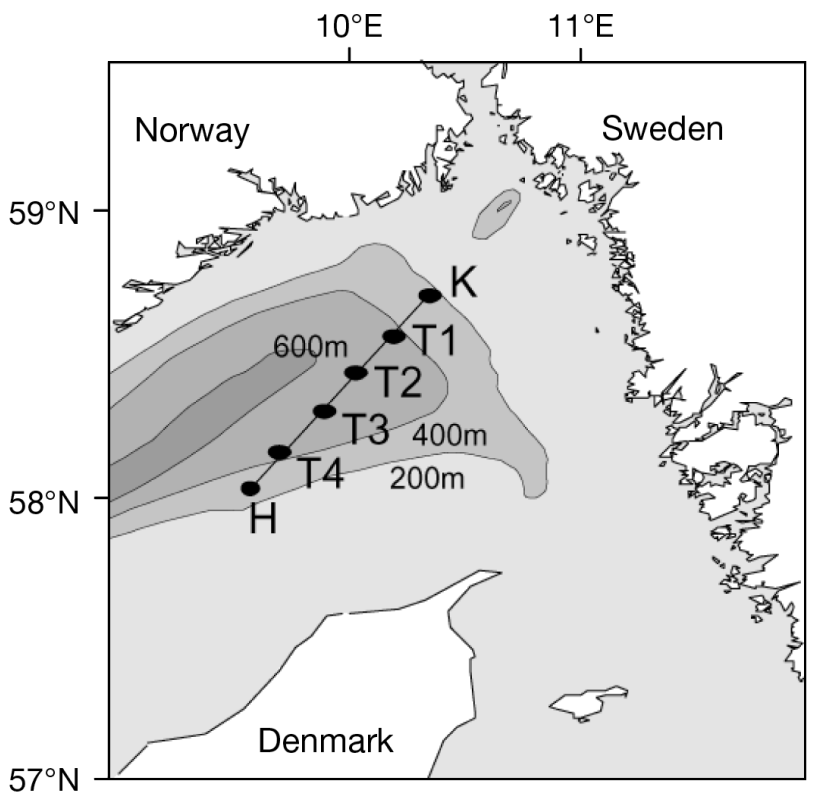

Fig. 1. Positions of the sampling stations in the Skagerrak 
Hydrography and turbulence. Profiles of temperature, salinity and fluorescence were measured using a CTD (Seabird 911 plus) equipped with a Wetstar fluorometer on all cruises. Microstructure velocity shear was measured with an MST profiler (Prandke \& Stips 1998, Stips 2005) from the Joint Research Centre on all cruises. The profiler was equipped with 2 velocity microstructure shear sensors (type PNS98), a microstructure temperature sensor, 3 standard CTD-sensors, and a sensor to measure horizontal acceleration of the profiler. The free-fall sinking velocity of the profiler was 0.7 to $0.8 \mathrm{~m} \mathrm{~s}^{-1}$. From the measurements from these instruments, the dissipation rate of turbulent kinetic energy $\varepsilon$ was computed (Stips 2005) over depth intervals of $0.5 \mathrm{~m}$ length and then averaged into $5 \mathrm{~m}$ intervals. Deployments of the profiler were made every 2 to $3 \mathrm{~h}$ on all cruises except for a period of ca. $24 \mathrm{~h}$ on 17 to 18 October in the North Sea due to rough sea conditions. Because of significant turbulence generation close to the ship, particularly in rough weather, data were considered reliable only below $10 \mathrm{~m}$ in the Skagerrak and $15 \mathrm{~m}$ in the North Sea.

Chlorophyll and protozooplankton. Chlorophyll a and phaeopigment concentrations were estimated for calibration of the in situ fluorometer for each cruise. Water samples were collected at 4 depths using 51 Niskin bottles mounted on a rosette sampler. Seawater (2 to 4 l) was filtered onto GF/F filters and extracted in $5 \mathrm{ml} 90 \%$ acetone for $24 \mathrm{~h}$ in the dark. Measurements were conducted before and after acidification on a spectrophotometer following the protocol description by Lorenzen (Strickland \& Parsons 1972). Chlorophyll a could then be estimated from the fluorescence profiles by linear calibration equations (Skagerrak 1999: $\mathrm{n}=24, \mathrm{r}^{2}=0.82, \mathrm{p}<0.01$; Skagerrak 2000: $\mathrm{n}=36, \mathrm{r}^{2}=$ $0.76, \mathrm{p}<0.01$; North Sea: $\left.\mathrm{n}=36, \mathrm{r}^{2}=0.12, \mathrm{p}<0.05\right)$. Protozooplankton are a potential food source for small copepods and water samples were taken to estimate their abundance at different depths. In the Skagerrak, samples were collected at the surface $(5 \mathrm{~m})$, the depth of the fluorescence maximum, and at $40 \mathrm{~m}$ below the pycnocline. In the North Sea, samples were taken from the mixed surface layer above the pycnocline $(17 \mathrm{~m})$ and within the pycnocline (40 to $50 \mathrm{~m}$ ). The samples were fixed in $2 \%$ Lugol's solution and settled in 10 or $50 \mathrm{ml}$ chambers for $24 \mathrm{~h}$ and counted and identified under an inverted microscope. Only protozooplankton $<100 \mu \mathrm{m}$ (excluding large dinoflagellates) were considered as prey available for the small copepods.

Mesozooplankton abundance and vertical distribution. Skagerrak: Mesozooplankton were collected within 5 depth strata $(0-10,10-25,25-40,40-60$ and 60-100 m) using a submersible pump (3000 $1 \mathrm{~min}^{-1}$ ) equipped with a $45 \mu \mathrm{m}$ net on both cruises. The pump was moved upwards at a rate of $10 \mathrm{~m} \mathrm{~min}^{-1}$ within each depth stratum. During spring, Stn H was sampled every $6 \mathrm{~h}$ over a $48 \mathrm{~h}$ period, starting at 06:00 h. During summer, Stns T1 and T2 were sampled once during night-time, Stn T2 was also sampled twice during daytime, while Stn T4 and T3 were sampled once during day-time.

North Sea: Mesozooplankton were collected at depths of $5,10,20,30,40,50,60$ and $80 \mathrm{~m}$, using a submersible pump (200 $1 \mathrm{~min}^{-1}$ ) equipped with a $40 \mu \mathrm{m}$ net. The pump was kept at the same depth position for 3 to $5 \mathrm{~min}$ while sampling. Samples were collected every 6 h, weather permitting. After 23 October, sampling was only conducted in the 40 to $50 \mathrm{~m}$ layer due to technical problems and these data were omitted from further analysis. The pump samples from all cruises were immediately fixed in a buffered formalinseawater solution ( 2 to $4 \% \mathrm{vol} / \mathrm{vol}$ ). In the laboratory, mesozooplankton abundance was counted by species, stages and sex in subsamples. In each sample, at least 100 individuals - or the entire sample — of the most abundant species were enumerated. It was not possible to distinguish between the different stages of Microsetella norwegica.

In order to study the vertical distributions of copepods with respect to different physiochemical factors, the depth of centre of mass $z_{C}$ of the vertical distribution was calculated (e.g. Fortier \& Leggett 1982, Lagadeuc et al. 1997). In each case, the centre of mass is the numerical estimate of

$$
z_{c}=\int_{-H}^{0} z C(z) \mathrm{d} z / \int_{-H}^{0} C(z) \mathrm{d} z
$$

where $C(z)$ is the measured concentration at depth $z$ and $H$ is total sampling depth. However, because the samples were collected in different manners (i.e. vertically integrated in the Skagerrak, compared to point samples in the North Sea) the estimates are also somewhat different. For Skagerrak data,

$$
z_{C}=\frac{1}{2} \frac{\sum\left(z_{n+1}-z_{n}\right)\left(z_{n+1}+z_{n}\right) C^{*}{ }_{n, n+1}}{\sum\left(z_{n+1}-z_{n}\right) C^{*}{ }_{n, n+1}}
$$

where $C^{*}{ }_{n, n+1}$ is the average concentration in the depth layer between $z_{n}$ and $z_{n+1}$. On the other hand, for the North Sea data,

$$
z_{C}=\frac{1}{6} \frac{\sum\left(z_{n+1}-z_{n}\right)\left(C_{n}\left(2 z_{n}+z_{n+1}\right)+C_{n+1}\left(2 z_{n+1}+z_{n}\right)\right)}{\sum\left(z_{n+1}-z_{n}\right)\left(C_{n+1}+C_{n}\right)}
$$

where $C_{n}$ is the concentration at $z_{n}$.

The $z_{C}$ 's were divided into day and night observations in the North Sea. In the Skagerrak, there was no significant diel vertical migration (see 'Results') and the day and night data were pooled to obtain enough replicates for further analysis. The effect of surface turbulence on $z_{C}$ was examined by a regression model: 


$$
z_{c}=a \log _{10}(\bar{\varepsilon})+b
$$

where $\bar{\varepsilon}$ is the average surface dissipation rate. Surface dissipation rate was estimated for the upper 10 to $20 \mathrm{~m}$ in the Skagerrak and 15 to $25 \mathrm{~m}$ in the North Sea. Thus, an increase in $z_{c}$ with increasing $\bar{\varepsilon}$ would indicate a deepening of the copepod distribution in response to high surface turbulence.

In order to distinguish whether this redistribution is due to passive turbulent mixing or active migration, we examine the relationship between surface turbulence and the coefficient of variance, $C V$ (= standard devia-
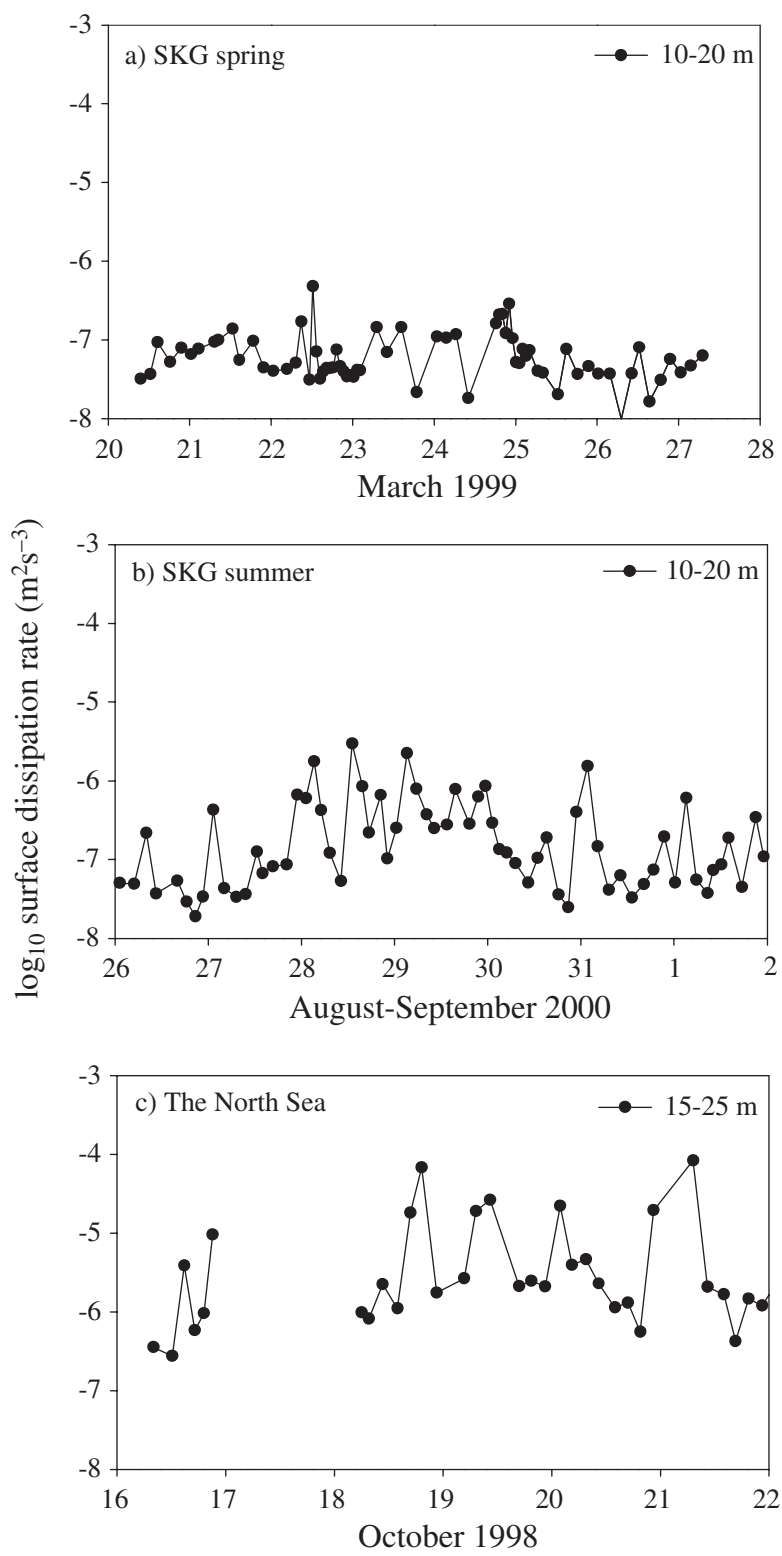

Fig. 2. Average surface dissipation rates during (a) spring and (b) summer in the Skagerrak (10 to $20 \mathrm{~m}$ ), and (c) in the North Sea (15 to $25 \mathrm{~m})$ tion (SD)/mean) (e.g. Maar et al. 2003) for the vertical distribution. If the increase in $z_{c}$ with increasing turbulence is due to passive mixing, we would expect $C V$ to decrease, indicating a more homogenized distribution. On the other hand, an increase in $C V$ with increasing turbulence would indicate active aggregation in response to surface turbulence.

Statistical analysis. For testing the difference between means, 1-way ANOVAs were applied with a type I error of $5 \%$ after checking for homogeneity in variance by Levene's test. Simple regression analyses were conducted using a type I error of $5 \%$ and the number of replicates $\mathrm{n}$ and the $\mathrm{r}^{2}$ are indicated in the text. All statistical tests were conducted using Statistical Package of Social Science (SPSS, version 11.5) for Windows.

\section{RESULTS}

\section{Environmental conditions}

Skagerrak, spring. Weather conditions were cloudy, snowy and calm. The average surface dissipation rates in the upper $20 \mathrm{~m}$ were accordingly relatively low, $<10^{-6} \mathrm{~m}^{2} \mathrm{~s}^{-3}$, with no apparent diel or tidal signal (Fig. 2a). Salinity in the uppermost 10 to $15 \mathrm{~m}$ was low due to outflowing Baltic Sea waters, and a halocline was located in the depth range 5 to $12 \mathrm{~m}$ (Fig. 3). Surface temperatures were low $\left(<5^{\circ} \mathrm{C}\right)$ increasing gradually towards the bottom. Maximum chlorophyll a concentrations were found in association with the pycnocline and varied between 10 and $25 \mathrm{\mu g} \mathrm{l}^{-1}$ (Fig. 3).

Skagerrak, summer. The sampling period was in general calm and the average surface dissipation rates $(10$ to $20 \mathrm{~m})$ were below $5 \times 10^{-6} \mathrm{~m}^{2} \mathrm{~s}^{-3}$ (Fig. 2b). The halocline was located slightly deeper than during spring (Fig. 4). The warming of the surface layer during summer enhanced the stable density stratification and, consequently, a strong pycnocline was found in the depth range 8 to $15 \mathrm{~m}$. There was no nocturnal convection because of cloud cover and relatively warm air temperature, resulting in negligible surface heat fluxes. Several deep chlorophyll a maxima ( 3 to $4 \mu \mathrm{g} \mathrm{l}^{-1}$ ) were recorded during summer in association with the pycnocline except for 2 occasions where a cold water patch located below the pycnocline caused elevated chlorophyll a concentrations $\left(17 \mu \mathrm{g} \mathrm{l}^{-1}\right)$.

North Sea. The sampling period was influenced by frequent and strong wind events separated by short periods of calm weather. The average surface dissipation rates varied accordingly from $10^{-7}$ to $10^{-4} \mathrm{~m}^{2} \mathrm{~s}^{-3}$ (Fig. 2c) and were primarily associated with surface 
The Skagerrak spring
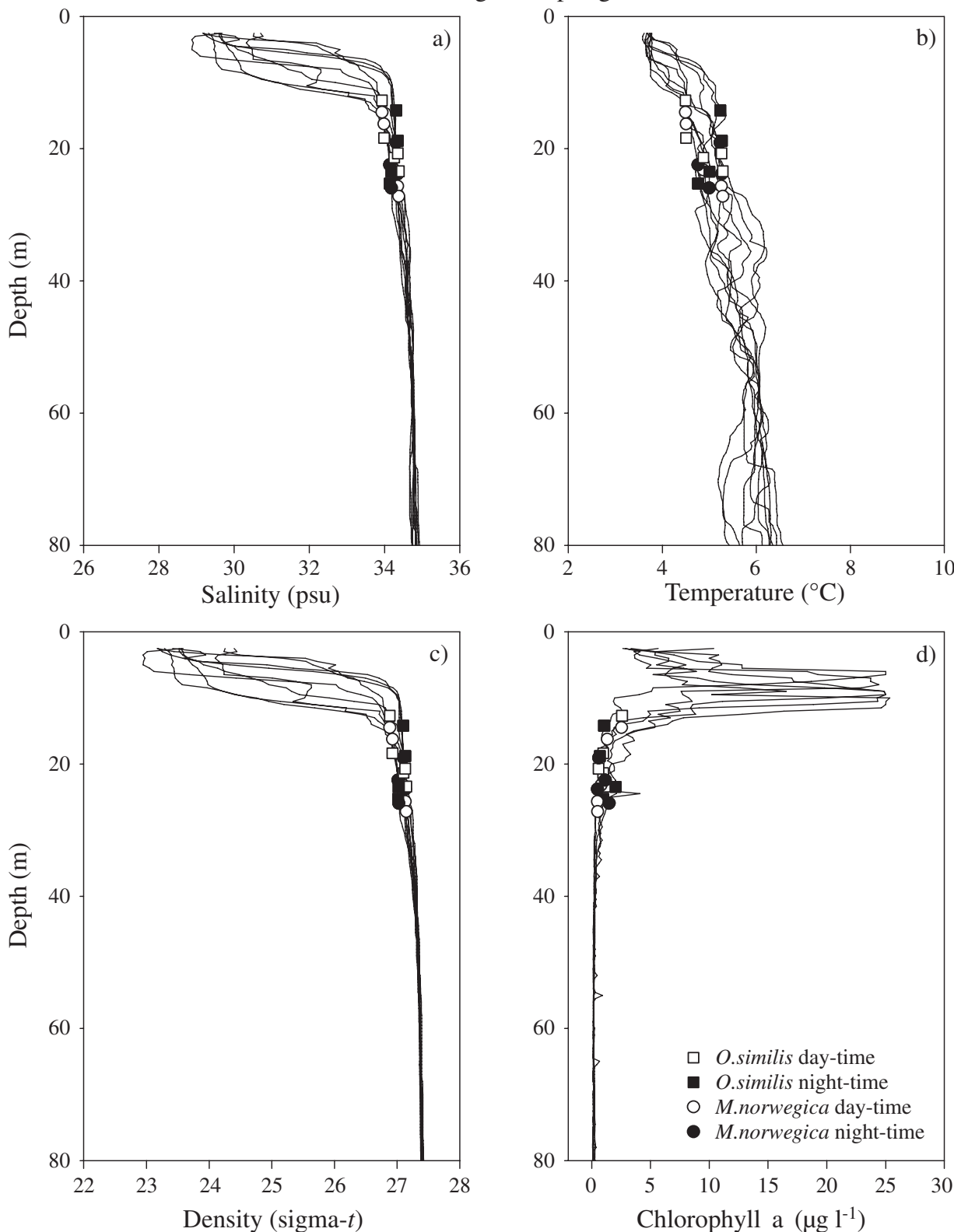

Fig. 3. Vertical profiles of (a) salinity, (b) temperature, (c) density and (d) chlorophyll a during spring at Stn $\mathrm{H}$ in the Skagerrak, and the related values (symbols) at the depths of centre of mass of Oithona similis and Microsetella norwegica during day and night time are shown

wind stress (Visser et al. 2001) with no statistically significant day-night variation ( $\mathrm{df}=21, \mathrm{p}=0.89$ ). The water column remained stratified with a strong pycnocline located at 40 to $60 \mathrm{~m}$ (Fig. 5), the depth of which varied little over the observation period. There was no significant relationship between surface turbulence and the depth of the mixed layer $\left(n=23, r^{2}<0.001, p=\right.$ 0.90). Chlorophyll a concentrations were slightly higher above the pycnocline $\left(0.5\right.$ to $\left.0.8 \mu \mathrm{g} \mathrm{l}^{-1}\right)$ than below $\left(>0.1 \mu \mathrm{g} \mathrm{l}^{-1}\right)$.

\section{Potential food sources}

Potential food sources for Oithona similis and Microsetella norwegica other than those associated with chlorophyll $a$ are protozooplankton, copepod nauplii, marine snow aggregates including discarded appendicularian houses and copepod faecal pellets. The abundance of protozooplankton $(<100 \mu \mathrm{m})$ was highest in the pycnocline in the Skagerrak and highest in the surface layer in the North Sea (Table 1). Cope- 
The Skagerrak summer
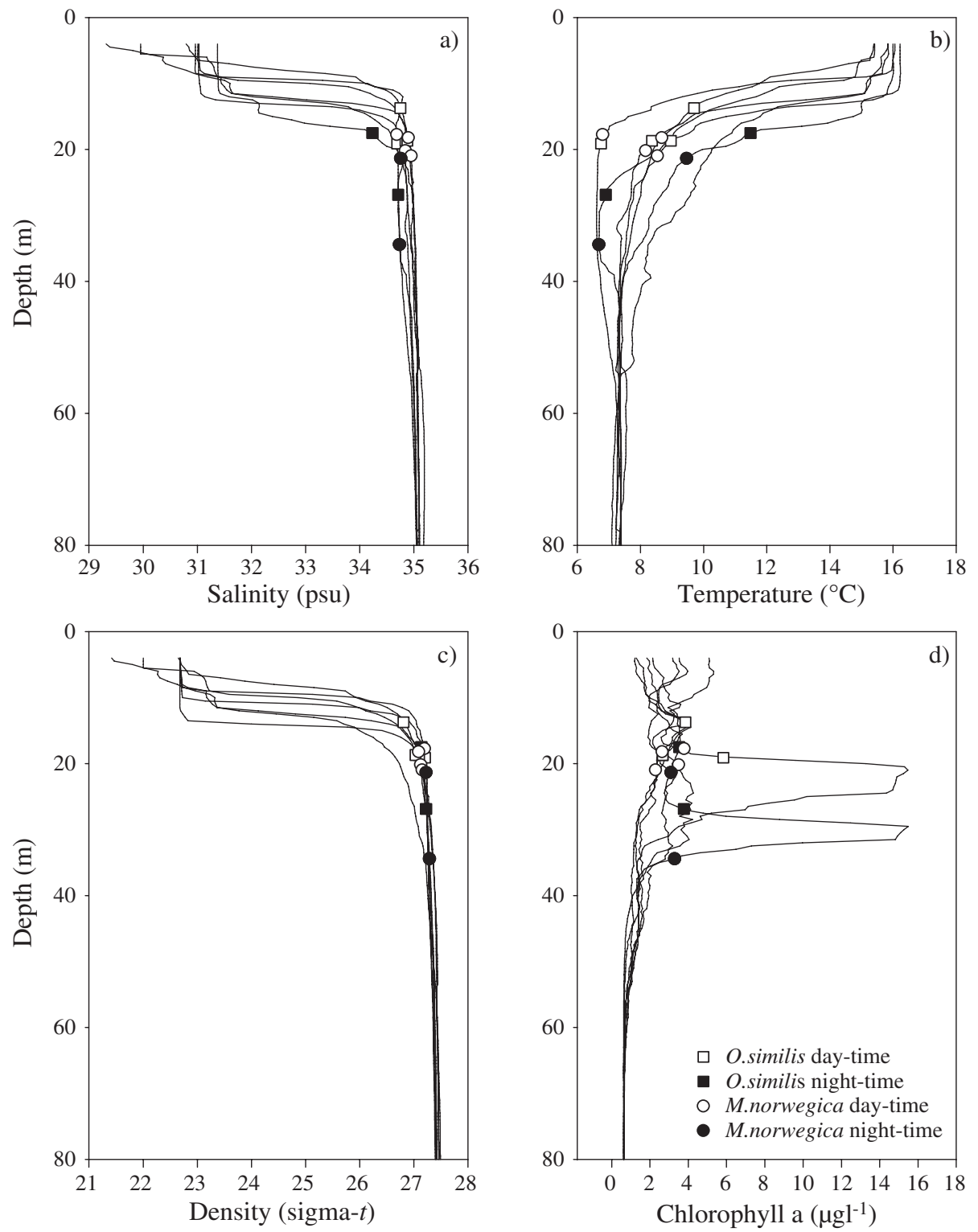

Fig. 4. Vertical profiles of (a) salinity, (b) temperature, (c) density and (d) chlorophyll a during summer at Stns T1 to T4 in the Skagerrak, and the related values (symbols) at the depths of centre of mass of Oithona similis and Microsetella norwegica during day and night time are shown

pod nauplii were present at the surface-pycnocline layers in the Skagerrak and were absent during autumn in the North Sea. The appendicularian Oikopleura dioica was found during summer in the Skagerrak with the highest abundance and hence production of mucus houses in the surface layer. The average depth of centre of mass of the calanoid copepods (CIII to CVI) was located between 7 and $22 \mathrm{~m}$ in the Skagerrak and between 22 and $38 \mathrm{~m}$ in the North Sea (Table 2). The calanoids, and hence their faecal pellet production, were found at similar depths as $O$. similis, and always located above $M$. norwegica.

\section{Vertical distribution of Oithona similis and Microsetella norwegica}

Oithona similis numerically dominated the copepod community during all cruises and Microsetella norwegica were also highly abundant in the Skagerrak. There was no significant diel vertical migration of $O$. similis females and copepodites in the Skagerrak $(\mathrm{df}=$ $14, p>0.26)$ and in the North Sea ( $d f=19, p>0.32)$ tested as the difference in $z_{c}$ between day and night time (Fig. 6, Table 2). The $z_{c}$ of $O$. similis females and copepodites (CI to CIV) varied between 12 and $27 \mathrm{~m}$ in 
The North Sea autumn
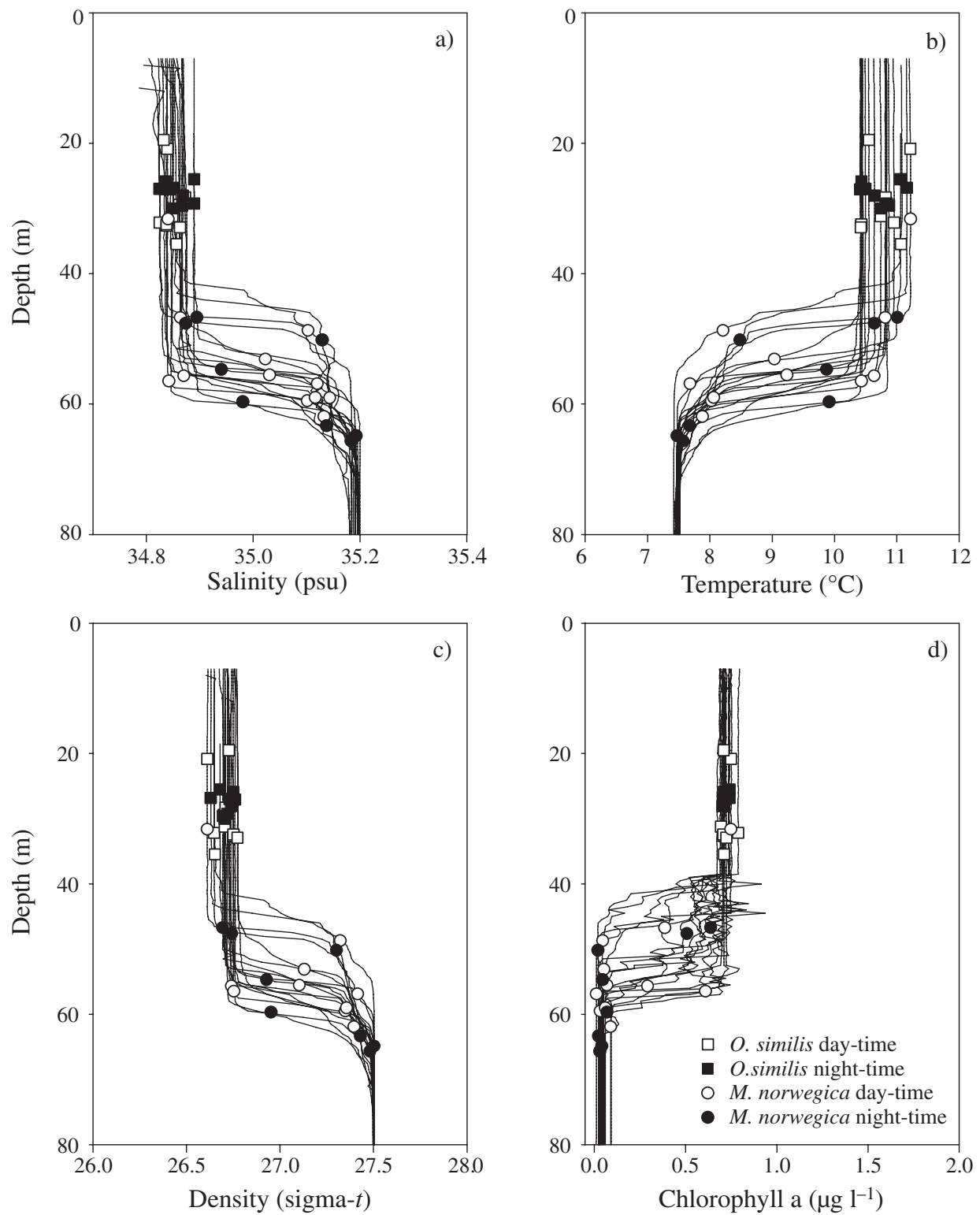

Fig. 5. Vertical profiles of (a) salinity, (b) temperature, (c) density and (d) chlorophyll $a$ at the anchor station in the North Sea, and the related values (symbols) at the depths of centre of mass of Oithona similis and Microsetella norwegica during day and night time are shown

the Skagerrak, and between 18 and $36 \mathrm{~m}$ in the North Sea (Fig. 7). The $z_{C}$ of females was located just below the pycnocline during both cruises in the Skagerrak (Figs. $3 \& 4$ ) and in the surface layer well above the pycnocline in the North Sea (Fig. 5).

The vertical distribution of Microsetella norwegica showed no significant day-night differences in the Skagerrak $(d f=14, p>0.13)$ and the North Sea $(d f=19, p>$ 0.67 ) (Fig. 6, Table 2). The $z_{C}$ varied between 15 and $34 \mathrm{~m}$ in the Skagerrak (Fig. 7) i.e. just below the pycnocline (Figs. 3 \& 4). In the North Sea, $z_{C}$ varied between 32 and $66 \mathrm{~m}$, which coincided with the pycnocline layer (Fig. 5).
We could find no consistent significant relationship between $z_{C}$ of either Microsetella norwegica or Oithona similis in either of the Skagerrak or North Sea data sets with respect to either surface salinity, temperature or chlorophyll a measurements (Table 3). The only exception was for $M$. norwegica in the North Sea for surface temperature. For the Skagerrak data, day-time profiles of $O$. similis (Fig. 6) show similar abundances within the low salinity surface waters ( 0 to $10 \mathrm{~m}$ ) compared to abundances below the halocline (10 to $25 \mathrm{~m})$. Indeed, O. similis copepodites seem to prefer the low salinity surface layer and we can 
Table 1. Average abundance (cells $\mathrm{l}^{-1}$ ) of protozooplankton (ciliates and dinoflagellates $<100 \mu \mathrm{m}$ ) and of copepod nauplii and appendicularians (ind. $\mathrm{l}^{-1}$ ) in the surface layer, pycnocline and below the pycnocline (SD in brackets). '-' denotes not measured

\begin{tabular}{|lccc|}
\hline & Surface & Pycnocline & $\begin{array}{c}\text { Below } \\
\text { pycnocline }\end{array}$ \\
\hline Skagerrak, spring & & & \\
Ciliates & $8400(3500)$ & $122000(7000)$ & $1800(600)$ \\
Dinoflagellates & $3800(2700)$ & $5900(3100)$ & $700(200)$ \\
Copepod nauplii & $127(7)$ & $55(2)$ & $2(1)$ \\
Appendicularia & - & - & - \\
Skagerrak, summer & $3000(1700)$ & $2200(1700)$ & $800(300)$ \\
Ciliates & $15000(3000)$ & $24000(9000)$ & $11000(4000)$ \\
Dinoflagellates & $9300(5400)$ & $3200(2000)$ \\
Copepod nauplii & $7900(3500)$ & $9.09(0.09)$ & $0.03(0.03)$ \\
Appendicularia & $0.50(0.50)$ & 0.09 & \\
North Sea & & & - \\
Ciliates & $2380(1200)$ & $1100(400)$ & - \\
Dinoflagellates & $4200(900)$ & $2100(1000)$ & - \\
Copepod nauplii & - & - & - \\
Appendicularia & - & - & - \\
Ciliates & $2380(1200)$ & $1100(400)$ & \\
\hline
\end{tabular}

conclude that salinity was not a barrier. Further, the salinity of this surface layer (29 to $32 \mathrm{psu}$ ) is well within the range of tolerance for these species (Andersen \& Nielsen 2002).

\section{Turbulence and vertical distributions}

The dissipation rates at the $z_{C}$ of Oithona similis females were $<3 \times 10^{6} \mathrm{~m}^{2} \mathrm{~s}^{-3}$ (Fig. 8, Table 4). There was a significant increase in $z_{C}$ of females and some copepodite stages with increasing surface dissipation rates, $\bar{\varepsilon}$, during summer in the Skagerrak (day and night samples) and in the North Sea during night-time (Table 5, Fig. 9). For North Sea day-time distributions, there was no significant relationship between $z_{c}$ and $\bar{\varepsilon}$ for any O. similis stages (Table 5). There was also no significant relationship between $z_{C}$ and $\bar{\varepsilon}$ in the Skagerrak during spring, when which $\bar{\varepsilon}$ was relatively low, not exceeding $10^{7} \mathrm{~m}^{2} \mathrm{~s}^{-3}$. For the North Sea data where it was possible to separate day and night samples, the coefficient of variance, $C V$, for $O$. similis showed a non-significant increase with increasing surface turbulence (day: $\mathrm{n}=11, \mathrm{r}^{2}=0.004, \mathrm{p}>0.80$, night: $\left.\mathrm{n}=9, \mathrm{r}^{2}=0.001, \mathrm{p}>0.90\right)$.

The $z_{c}$ of Microsetella norwegica was located at depths with a dissipation rate of $<3 \times 10^{7} \mathrm{~m}^{2} \mathrm{~s}^{-3}$ (Fig. 10, Table 4). There was a significant increase in $z_{C}$ with increasing $\bar{\varepsilon}$ in the Skagerrak during summer and in the
North Sea during day-time (Table 5, Fig. 11), while there was no significant relationship either in the Skagerrak during spring, where $\bar{\varepsilon}$ did not exceed $10^{7} \mathrm{~m}^{2} \mathrm{~s}^{3}$, or in the North Sea during nighttime. For the North Sea data, the coefficient of variance for $M$. norwegica showed a marginally significant increase with increasing surface turbulence during day-time $\left(\mathrm{n}=11, \mathrm{r}^{2}=0.14, \mathrm{p}=0.20\right)$ and a negligible correlation at night $\left(\mathrm{n}=9, \mathrm{r}^{2}<\right.$ 0.001, $\mathrm{p}=0.90$ ).

The key calanoid copepods were Calanus spp., Centropages typicus, Paracalanus parvus and Pseudocalanus spp. The $z_{C}$ of Calanus spp. stage $\mathrm{CIV}$ to $\mathrm{CV}$ increased with increasing $\bar{\varepsilon}$ in the North Sea during night-time $\left(\mathrm{r}^{2}=0.67, \mathrm{p}<0.01\right)$. We found no other correlations between $z_{C}$ and $\bar{\varepsilon}$ of the other calanoid species tested for stages CIII, CIV, CV and adults.

\section{DISCUSSION}

\section{Vertical distributions}

Even though the small copepods Oithona similis and Microsetella norwegica are widely distributed and often numerically dominate the copepod community, factors affecting their vertical distribution and the role they play in carbon cycling are not yet fully understood (Turner 2004). In the present study, the $z_{C}$ of $O$. similis was found in association with the shallow pycnocline in the Skagerrak and at the surface layer in the North Sea. Here this species could exploit the observed high abundance of microzooplankton or sinking faecal pellets produced by calanoid copepods (González \& Smetacek 1994, Nielsen \& Sabatini 1996). The harpacticoid copepod $M$. norwegica has been observed in association with marine snow aggregates in natural waters (Alldredge 1972, Green \& Dagg 1997) and a recent experimental study confirms that $M$. norwegica colonize and feed on enriched agar aggregates, while

Table 2. Average \pm SD depth $(\mathrm{m})$ of centre of mass of Oithona similis (CI to CVI), Microsetella norwegica and the most abundant calanoid copepods (CIII to CVI) in the Skagerrak (spring + summer) and the North Sea

\begin{tabular}{|c|c|c|c|c|}
\hline & \multicolumn{2}{|c|}{ Skagerrak spring + summer } & \multicolumn{2}{|c|}{ North Sea } \\
\hline & Day-time & Night-time & Day-time & Night-time \\
\hline O. similis & $18.5 \pm 3.4$ & $21.0 \pm 4.9$ & $29.3 \pm 5.1$ & $27.7 \pm 1.8$ \\
\hline M. norwegica & $20.4 \pm 4.3$ & $24.5 \pm 2.4$ & $53.2 \pm 8.4$ & $56.9 \pm 7.4$ \\
\hline Calanus spp. & $18.3 \pm 11.8$ & $13.5 \pm 9.8$ & $36.8 \pm 5.6$ & $38.3 \pm 3.8$ \\
\hline Centropages typicus & $6.7 \pm 2.4$ & $10.8 \pm 9.6$ & $21.8 \pm 5.6$ & $27.8 \pm 6.5$ \\
\hline Paracalanus parvus & $15.2 \pm 7.2$ & $21.7 \pm 10.1$ & $25.7 \pm 5.1$ & $31.9 \pm 4.1$ \\
\hline Pseudocalanus spp. & $12.0 \pm 3.5$ & $13.9 \pm 7.3$ & $25.0 \pm 6.1$ & $31.5 \pm 3.3$ \\
\hline
\end{tabular}


they feed inefficiently on suspended food (Koski et al. 2005). The $z_{C}$ of $M$. norwegica was found within or just below the pycnocline, where there may be an accumulation of aggregates due to the density gradient (Alldredge et al. 2002). Thus, both species occupied water column layers with suitable food.
Both Oithona similis and Microsetella norwegica appear to actively migrate downwards in the water column to avoid high turbulence levels in the surface. This was seen at 2 different geographical locations, and at 2 different times of year. While this observed behaviour could be in response to other physiochemical water col-

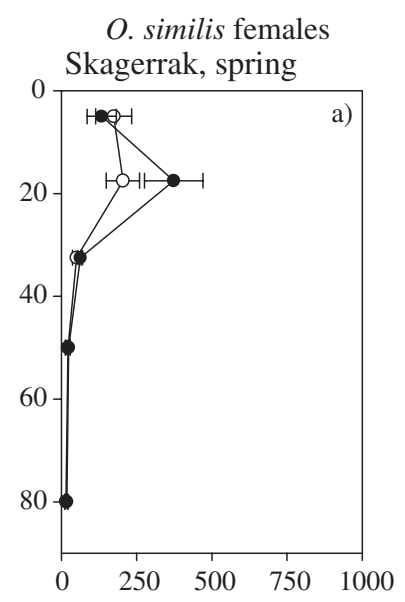

O. similis copepodites

M. norwegica
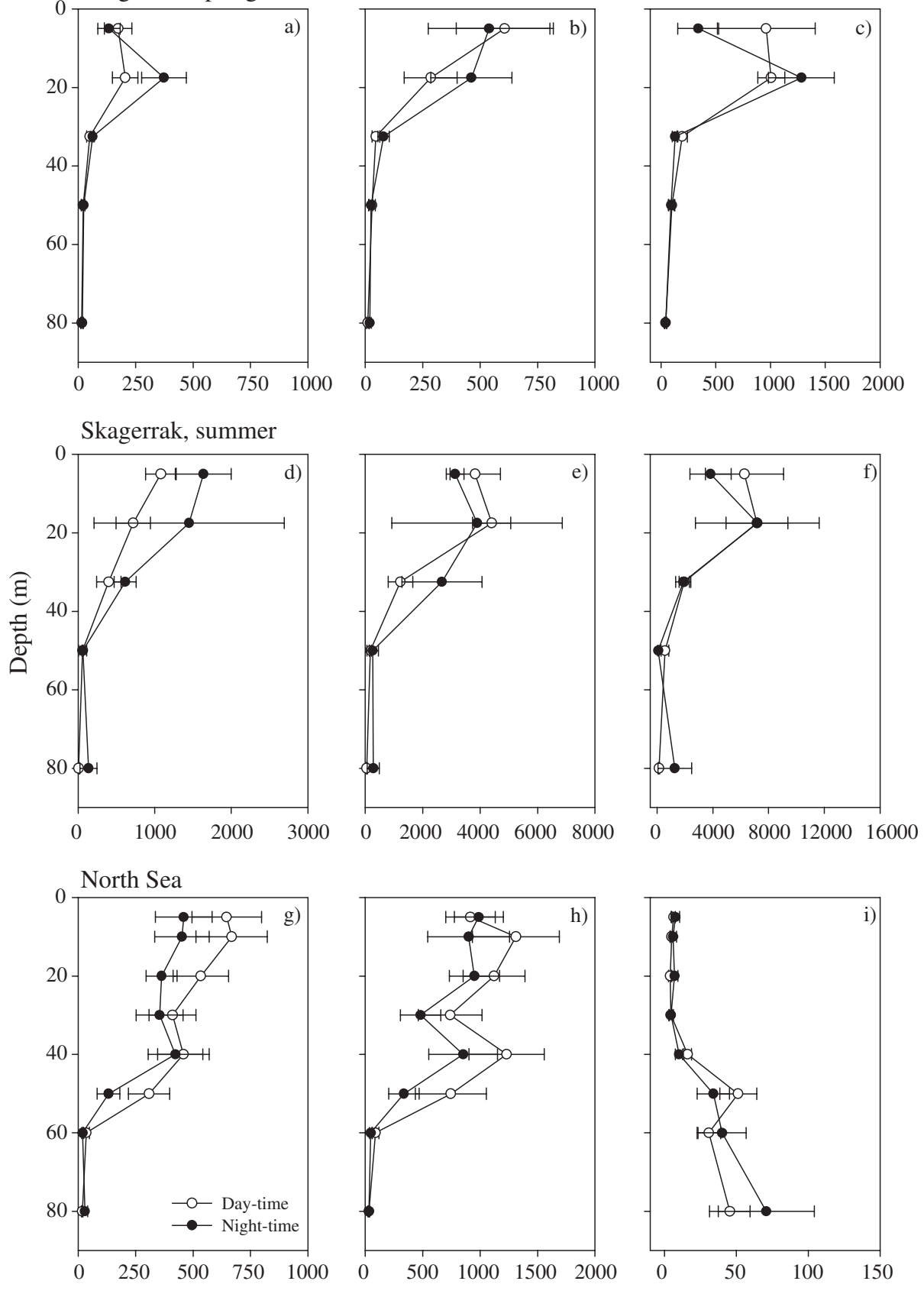

Abundance (individuals $\mathrm{m}^{-3}$ )

Fig. 6. Average $( \pm \mathrm{SE})$ vertical distribution (ind. $\left.\mathrm{m}^{-3}\right)$ of $(\mathrm{a}, \mathrm{d}, \mathrm{g})$ Oithona similis females and (b,e,f) copepodites $(\mathrm{CI}$ to $\mathrm{CV})$ and $(\mathrm{c}, \mathrm{f}, \mathrm{i})$ Microsetella norwegica during day and night time during: $(\mathrm{a}, \mathrm{b}, \mathrm{c})$ spring $(\mathrm{n}=5,4)$ and $(\mathrm{d}, \mathrm{e}, \mathrm{f})$ summer $(\mathrm{n}=4,2)$ in the Skagerrak, and $(g, h, i)$ in the North Sea $(n=11,9)$ 

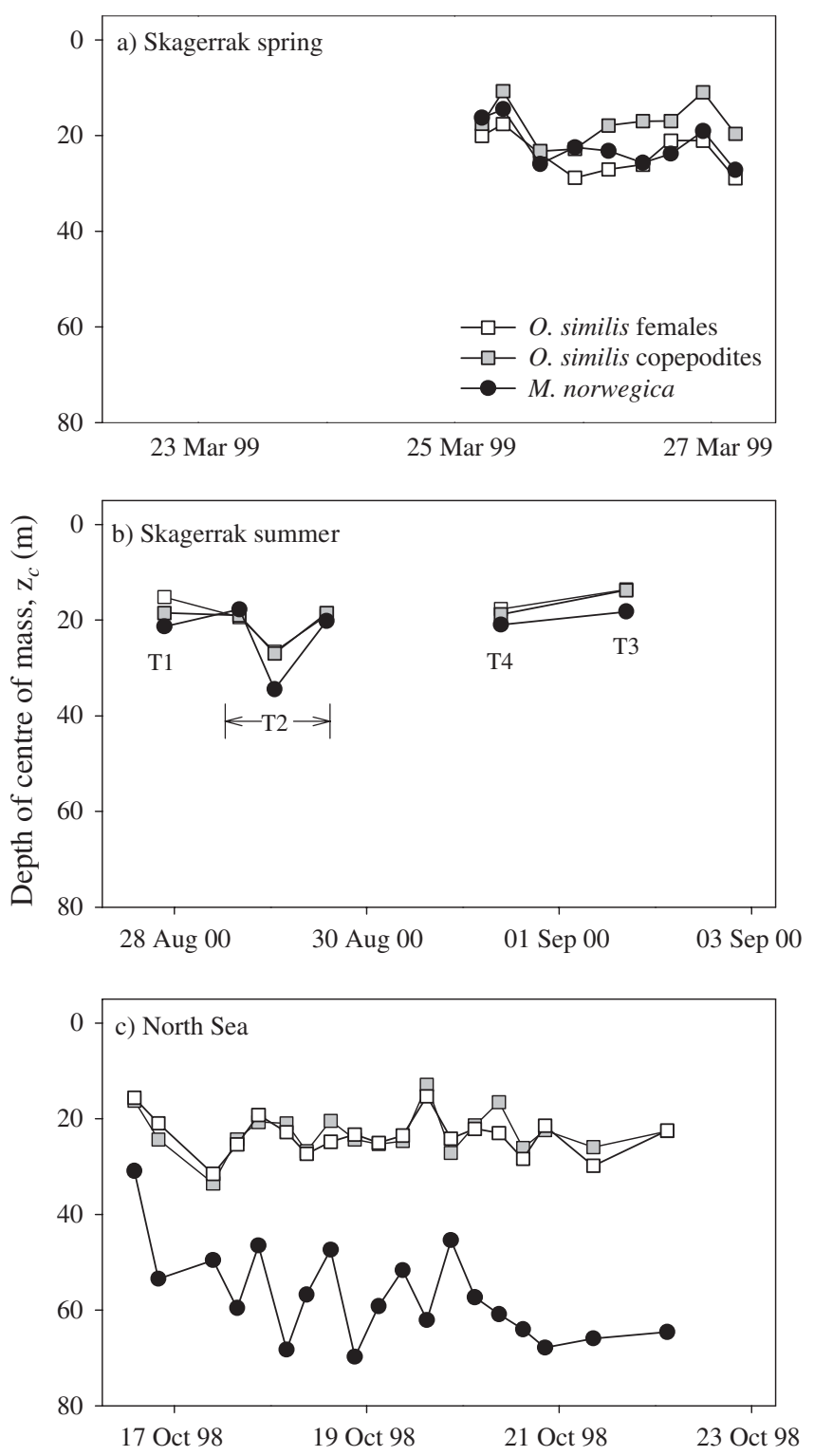

Fig. 7. Depths of centre of mass of Oithona similis females and copepodites (CI to CV) and Microsetella norwegica during (a) spring, Stn H Skagerrak and (b) summer, Stns T1-T4, Skagerrak and (c) anchor station, North Sea

umn variables (e.g. temperature, salinity or chlorophyll a), the turbulence-avoidance hypothesis appears to present the most consistent results. Similar turbulence avoidance behaviour has previously been reported for a variety of copepod species such as Temora longicornis and Pseudocalanus sp. (Lagadeuc et al. 1997), for copepodite stages of Temora spp., Oithona spp., Pseudocalanus spp. and Calanus finmarchicus (Incze et al. 2001), and for early copepodite stages of calanoid copepods (Reiss et al. 2002). For our North Sea data at least, this is an active behavioural response rather than a pas- sive effect (e.g. due to turbulent vertical mixing), as it only appears at certain times during the day-night cycle. That is, if the observed vertical variation in centre of mass were due to a passive response to turbulence, it should appear at all times. In addition, the coefficient of variance for the vertical distributions either increased or remained the same with increasing surface turbulence, further supporting the conclusion that the change in centre of mass was not due to turbulent mixing. Both $O$. similis and $M$. norwegica with typical swimming speeds of $1 \mathrm{~mm} \mathrm{~s}^{-1}$ (Svensen \& Kiørboe 2000, Koski et al. 2005) should also be able to overcome the turbulent mixing at $\varepsilon<10^{-6} \mathrm{~m}^{2} \mathrm{~s}^{-3}$ (Haury et al. 1990, Yamazaki \& Squires 1996, Lagadeuc et al. 1997) corresponding to the maximum level of $\varepsilon$ measured at $z_{c}$ (Table 4). We acknowledge that factors other than turbulence such as predators, food quality, light regime etc. may influence our results. However, the driving factors shaping the vertical distributions of copepods are often difficult to determine, as seen in for example diel vertical migration studies (Irigoien et al. 2004). The question is what benefit these organisms derived from this response to turbulence.

\section{Ambush predator and hydromechanical signals}

Oithona similis are strictly ambush feeders using hydromechanical detection of prey (Svensen \& Kiørboe 2000, Saiz et al. 2003). Ambush predators hang quietly in the water while slowly sinking and scanning their

Table 3. Significance level of linear regressions of depth of centre of mass versus surface averaged (upper $20 \mathrm{~m}$ ) water column properties. ${ }^{*} \mathrm{p}<0.05$

\begin{tabular}{|c|c|c|c|}
\hline & & & p-level \\
\hline \multirow{6}{*}{$\begin{array}{l}\text { Skagerrak } \\
\text { spring }\end{array}$} & \multirow[t]{3}{*}{ O. similis females } & Salinity & 0.30 \\
\hline & & Temperature & 0.32 \\
\hline & & Chlorophyll & 0.69 \\
\hline & \multirow[t]{3}{*}{ M. norwegica } & Salinity & 0.54 \\
\hline & & Temperature & 0.65 \\
\hline & & Chlorophyll & 0.49 \\
\hline \multirow{6}{*}{$\begin{array}{l}\text { Skagerrak } \\
\text { summer }\end{array}$} & \multirow{3}{*}{ O. similis females } & Salinity & 0.26 \\
\hline & & Temperature & 0.53 \\
\hline & & Chlorophyll & 0.89 \\
\hline & \multirow[t]{3}{*}{ M. norwegica } & Salinity & 0.22 \\
\hline & & Temperature & 0.33 \\
\hline & & Chlorophyll & 0.91 \\
\hline \multirow[t]{6}{*}{ North Sea } & \multirow[t]{3}{*}{ O. similis females } & Salinity & 0.50 \\
\hline & & Temperature & 0.55 \\
\hline & & Chlorophyll & 0.85 \\
\hline & \multirow[t]{3}{*}{ M. norwegica } & Salinity & 0.40 \\
\hline & & Temperature & $0.02^{*}$ \\
\hline & & Chlorophyll & 0.20 \\
\hline
\end{tabular}




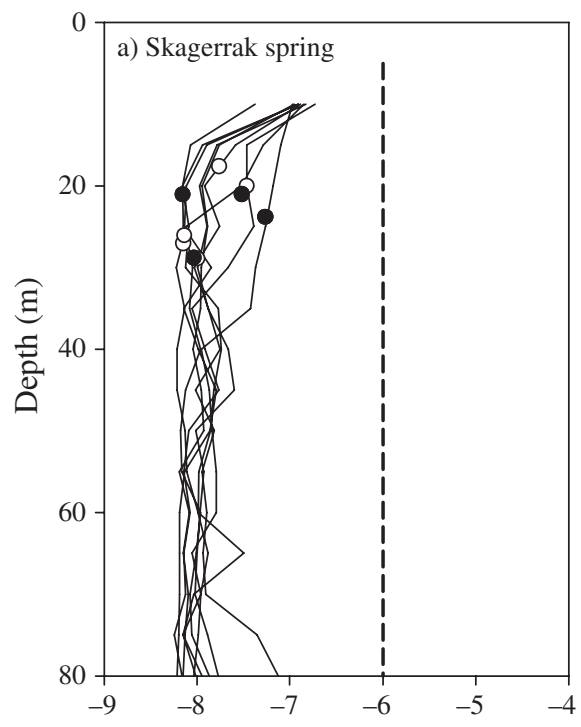

O. similis females

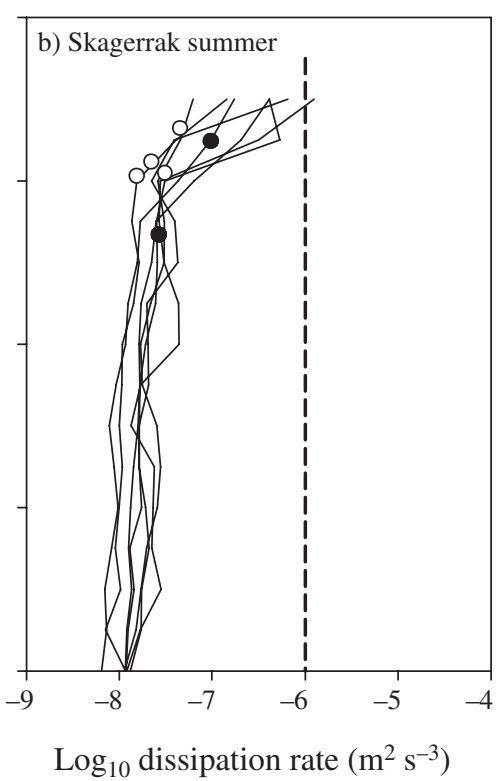

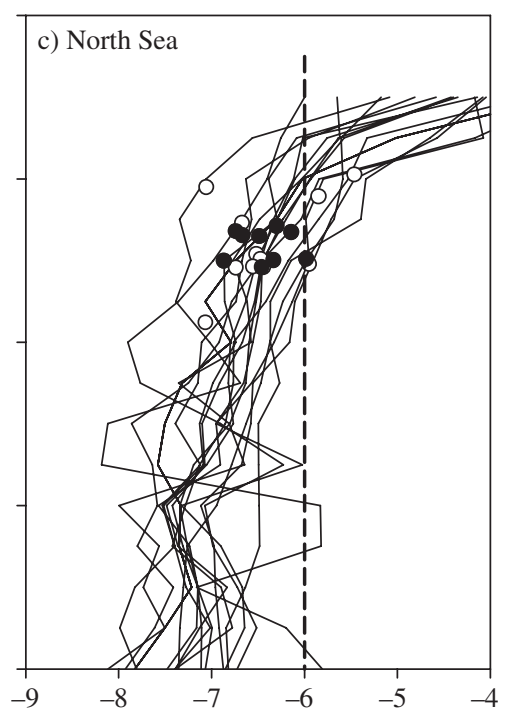

Fig. 8. Oithona similis. Vertical profiles of dissipation rates (log scale) and depth of centre of mass of females during (O) day time and (•) night time during: (a) spring in the Skagerrak (b) summer in the Skagerrak, and (c) in the North Sea. Dashed line shows the maximum turbulence level at the depth of centre of mass

surroundings for motile prey, which they attack when located. Theoretical considerations (Rothschild \& Osborn 1988) suggest that the encounter rate, $Z$, of ambush predators and their motile prey (swimming speed $u$, concentration $C$ ) increases with turbulence for a given detection distance $R$. This can be summarized in the equation (Evans 1989):

$$
Z=\pi C R^{2}\left(u^{2}+2 w^{2}\right)^{1 / 2}
$$

where $W=\alpha(\varepsilon R)^{1 / 3}$ is the turbulent velocity at the detection distance scale, $\varepsilon$ is the turbulent dissipation rate and $\alpha$ is a constant of order 1 (Visser \& MacKenzie 1998). The implication here is that at prey concentrations less than saturation, ingestion rates would increase with turbulent intensity. This prediction is in stark contrast to observations which tend to show a dome shaped or even negative relationship of ingestion (or clearance) with turbulence (Saiz \& Kiørboe 1995, Caparroy et al. 1998, Saiz et al. 2003). In order to resolve this, it should be noted that turbulence can impair the detection ability of ambush predators that rely on hydromechanical signals to detect moving prey. Assuming that the signal-to-noise ratio must exceed $\kappa$, the reaction distance can be written as a function of turbulence:

$$
R(\varepsilon)=R_{0}\left(\frac{S}{\kappa W^{*}+S}\right)^{1 / 2}
$$

(Visser 2001) where $s$ is the inherent sensitivity of the predator (i.e. the threshold velocity it can detect), $w^{*}$ is

Table 4. Ranges in salinity (psu), temperature $\left({ }^{\circ} \mathrm{C}\right)$, density (sigma- $t$ ), chlorophyll $a\left(\mu g \mathrm{l}^{-1}\right)$ and dissipation rate $\left(\mathrm{m}^{2} \mathrm{~s}^{-3}\right)$ at the depth of centre of mass of Oithona similis females and Microsetella norwegica during spring and summer in the Skagerrak (SKG) and in the North Sea

\begin{tabular}{|llccccc|}
\hline & & Salinity & Temperature & Density & Chlorophyll a & Dissipation \\
\hline O. similis & SKG spring & $33.9-34.3$ & $4.5-5.2$ & $26.8-27.1$ & $0.6-2.6$ & $7 \times 10^{-9}-5 \times 10^{-8}$ \\
& SKG summer & $34.2-34.9$ & $6.8-11.5$ & $26.8-27.2$ & $2.7-5.8$ & $2 \times 10^{-8}-5 \times 10^{-8}$ \\
& North Sea & $34.8-34.9$ & $10.4-11.2$ & $26.6-26.8$ & $0.1-0.8$ & $9 \times 10^{-8}-3 \times 10^{-6}$ \\
& Total range & $32.2-34.9$ & $4.5-11.2$ & $26.6-27.2$ & $0.1-5.8$ & $7 \times 10^{-9}-3 \times 10^{-6}$ \\
M. norwegica & SKG spring & $33.9-34.4$ & $4.5-5.3$ & $26.9-27.1$ & $0.5-5.0$ & $7 \times 10^{-9}-5 \times 10^{-8}$ \\
& SKG summer & $34.7-35.0$ & $6.7-9.5$ & $27.1-27.3$ & $2.3-3.8$ & $2 \times 10^{-8}-4 \times 10^{-8}$ \\
& North Sea & $34.8-35.2$ & $7.5-11.2$ & $26.6-27.5$ & $0.0-0.8$ & $1 \times 10^{-8}-3 \times 10^{-7}$ \\
& Total range & $33.9-35.2$ & $4.5-11.2$ & $26.6-27.5$ & $0.0-5.0$ & $7 \times 10^{-9}-3 \times 10^{-7}$ \\
\hline
\end{tabular}




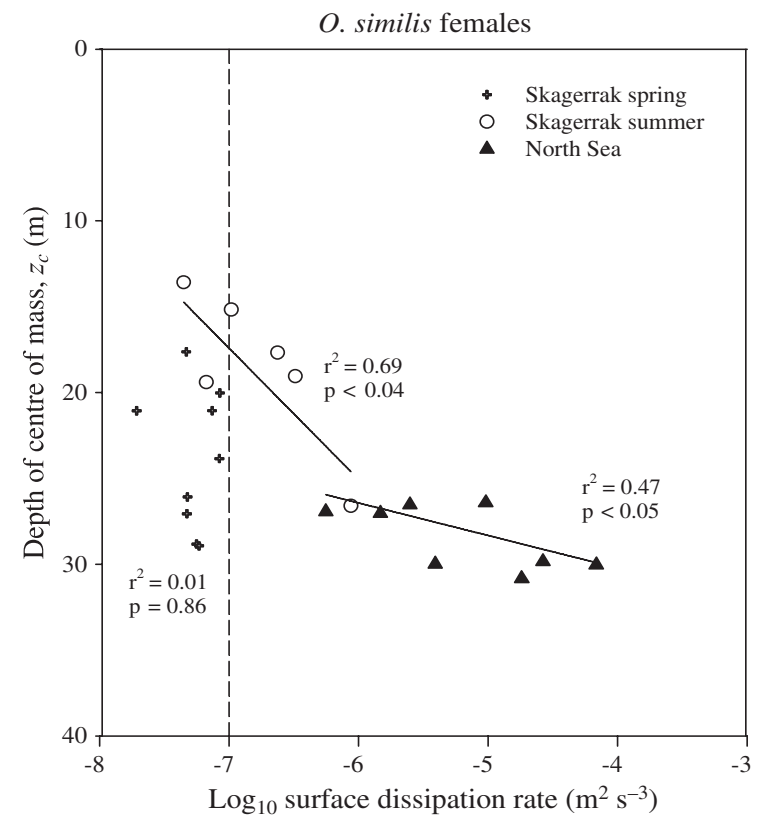

Fig. 9. Oithona similis. Depth of centre of mass of females versus average surface dissipation rates in the Skagerrak and the North Sea. Solid lines are regressions. Dashed line shows the suggested surface turbulence level which triggers an avoidance response by $O$. similis the turbulent velocity on the scale of the predator's sensory array, and $R_{0}$ is the detection distance in the absence of turbulence. Fig. 12 illustrates the predicted clearance $\left(\beta=Z C^{-1}\right)$ as a function of turbulent dissipation rate, for a copepod with antenna length scale $500 \mu \mathrm{m}$ (e.g. Oithona spp.) detecting a $100 \mu \mathrm{m}$ ciliate swimming at speed $400 \mu \mathrm{m} \mathrm{s}^{-1}$. The clearance is calculated for 3 different sensitivities (20,40 and $100 \mu \mathrm{m} \mathrm{s}^{-1}$ ) corresponding to observed neurological sensitivity (Yen et al. 1992) and deduced behavioural sensitivity (Kiørboe \& Visser 1999) for copepods. The calculated clearance decreases with increasing turbulence and any advantage of high sensitivity is rapidly lost as turbulence increases. These results reflect negative effects of turbulence on clearance rates in ambush predators as found in laboratory studies (Kiørboe \& Saiz 1995, Caparroy et al. 1998, Saiz et al. 2003) and are consistent with the observed range in clearance rates by Oithona davisae of 2 to $12 \mathrm{ml} \mathrm{d}^{-1}$ for $\varepsilon \sim 10^{-8}$ to $10^{-5} \mathrm{~m}^{2} \mathrm{~s}^{-3}$ (Saiz et al. 2003).

We suggest a threshold of surface turbulence equal to $\varepsilon \sim 10^{-7}-10^{-6} \mathrm{~m}^{2} \mathrm{~s}^{-3}$, where turbulence is critical for feeding as seen from the model results (Fig. 12). According to our observations (Figs. 8 \& 9), surface turbulence at or above this threshold level appears to trigger an avoidance response in Oithona similis. Below this threshold (e.g. Skagerrak, spring 1999), O. similis were widely distributed in the surface layer irrespective of the turbulence level. In comparison, the ambush feeder Centropages typicus was unaffected by turbulence despite its similar distribution in the North Sea (Table 2). This supports the idea that Oithona spp. are more sensitive to turbulence than calanoid ambush feeders (Saiz et al. 2003). The reason for this is likely to be that Oithona spp. are confined to ambush feeding, while the calanoid copepodites can shift between ambush and suspension feeding modes according to the current food and turbulence conditions (Saiz et al. 2003).

\section{Cruising with plume detection}

Sinking detrital material, such as faecal pellets, marine snow and discarded appendicularian houses, leaves a trail of organic solutes that chemosensory copepods can track to 

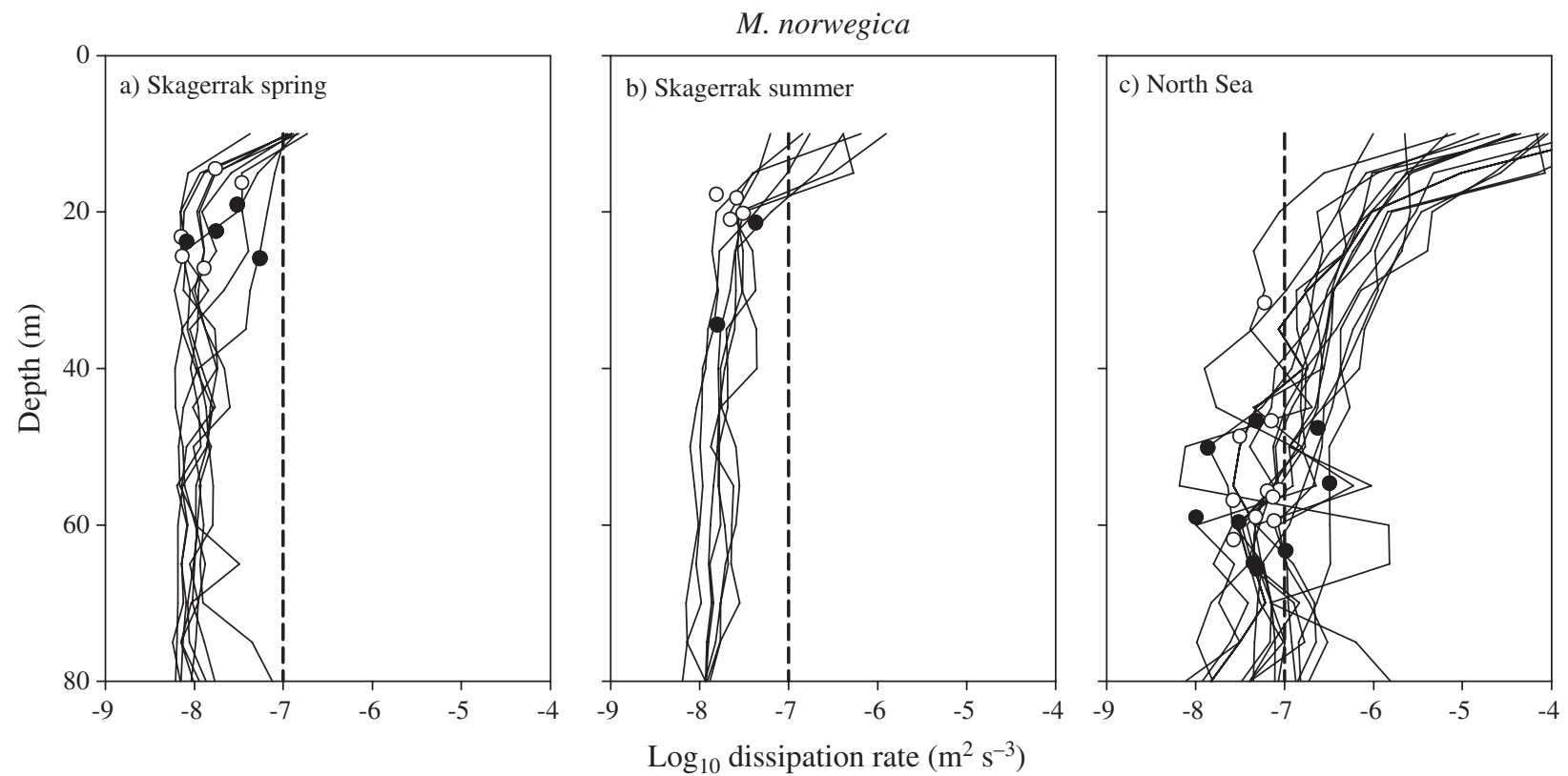

Fig. 10. Microsetella norwegica. Vertical profiles of dissipation rates (log scale) and depth of centre of mass during (O) day time and ( $)$ night time during: (a) spring in the Skagerrak (b) summer in the Skagerrak, and (c) in the North Sea. Dashed line shows the maximum turbulence level at depth of centre of mass

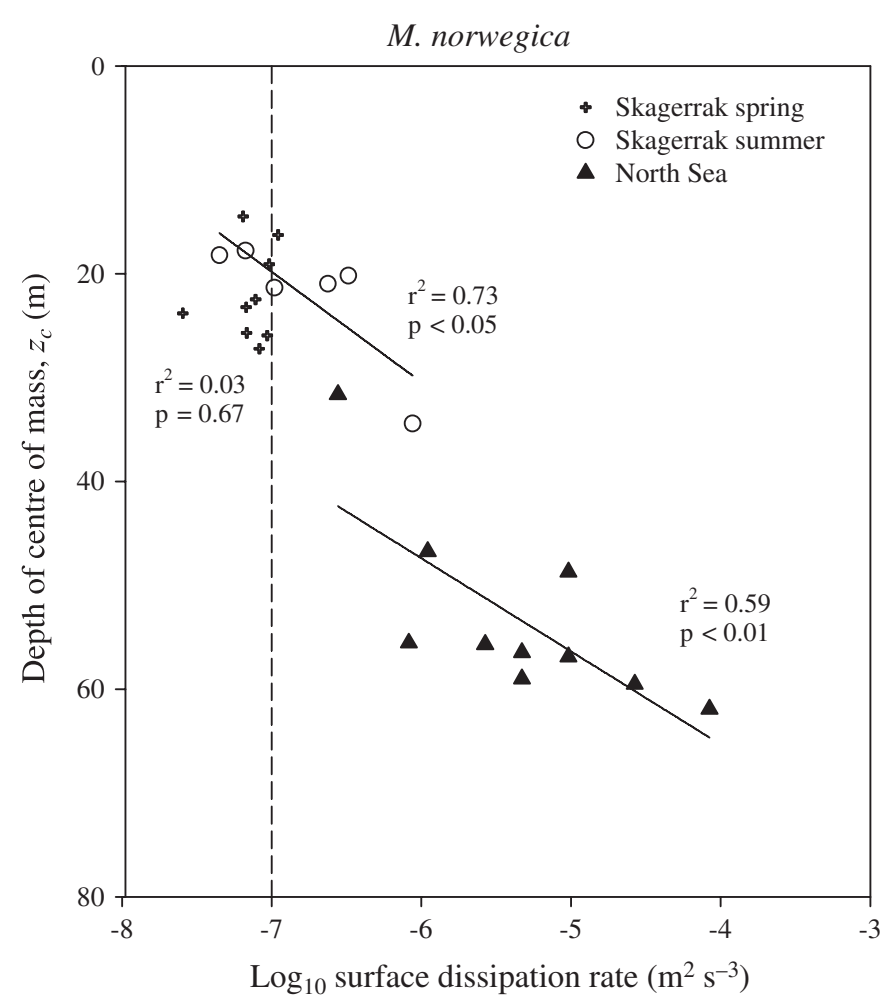

Fig. 11. Microsetella norwegica. Depth of centre of mass versus average surface dissipation rates in the Skagerrak (10 to $20 \mathrm{~m}$ ) and the North Sea (15 to $25 \mathrm{~m}$ ), where solid lines are regressions. Dashed line shows suggested turbulence level which triggers an avoidance response their source (Kiørboe \& Thygesen 2001). We here assume that Microsetella norwegica use remote chemical detection since theoretical computations suggest that this encounter mechanism is the only means by which sufficient encounters can be achieved to account for the reported high clearance of aggregates (Kiørboe 2000, Kiørboe \& Thygesen 2001, Koski et al. 2005). The parameters of the trailing plume that are relevant for the copepod encounter process are the plume length and its cross sectional area projected on to the vertical plane (Jackson \& Kiørboe 2003). Both of these may be expected to vary considerably with turbulence as the plume becomes stretched and disrupted (Visser \& Jackson 2004). In what follows, we use the empirical formulae reported by Visser \& Jackson (2004) to calculate the relevant plume parameters as a function of turbulent dissipation rate. Throughout we assume a particle radius of $0.2 \mathrm{~cm}$, a leakage rate of $9 \times$ $10^{-14} \mathrm{~mol} \mathrm{~s}^{-1}$, and a detection threshold of $3 \times 10^{-8} \mu \mathrm{M}$ (Jackson \& Kiørboe 2003).

The cross sectional area $\sigma$ of a chemical plume behind a sinking appendicularian house decreases with increasing turbulence (Fig. 13). For an Oikopleura dioica house sinking at around $10 \mathrm{~m} \mathrm{~d}^{-1}$ (Tagushi 1982, Maar et al. 2004), the cross section of the plume is 10 times greater at relatively low turbulence $\left(\varepsilon=10^{-8}\right.$ $\left.\mathrm{m}^{2} \mathrm{~s}^{-3}\right)$ than it is at higher turbulence levels $\left(10^{-6} \mathrm{~m}^{2}\right.$ $\mathrm{s}^{-3}$ ). This is consistent with our study, where Microsetella norwegica seemed to avoid turbulent 


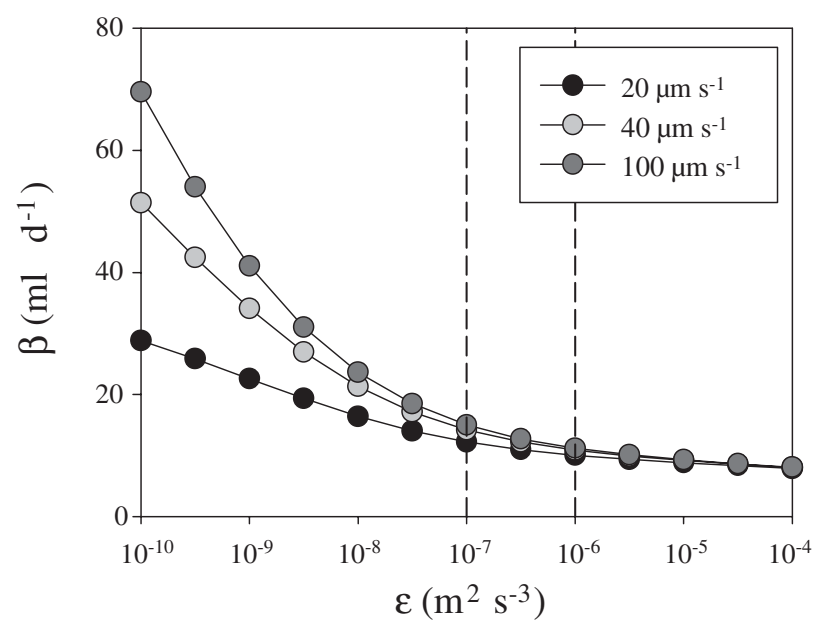

Fig. 12. Predicted clearance versus turbulent dissipation rate for advective encounter calculated for 3 different sensitivities 20, 40 and $100 \mu \mathrm{m} \mathrm{s}^{-1}$ (Eqs. 5 \& 6). Parameter settings are for an ambush copepod (antenna length $500 \mu \mathrm{m}$ ) feeding on motile prey (radius $100 \mu \mathrm{m}$, swimming speed $400 \mu \mathrm{m} \mathrm{s}^{-1}$, turning period $0.1 \mathrm{~s}$ ). At a hydromechanical sensitivity of $40 \mu \mathrm{m}$ $\mathrm{s}^{-1}$, this gives a reaction distance of $R_{0}=0.1 \mathrm{~cm}$ in the absence of turbulence. Vertical dashed lines indicate the suggested turbulence threshold of $10^{-7}$ to $10^{-6} \mathrm{~m}^{2} \mathrm{~s}^{-3}$ for triggering an avoidance response

layers of $\varepsilon>10^{7} \mathrm{~m}^{2} \mathrm{~s}^{-3}$ (Fig. 11). The rate at which copepods encounter discarded houses constrains the rate at which the animals can consume the houses. A copepod swimming horizontally at a speed $V$ has an encounter kernel, i.e. clearance rate, given by:

$$
\beta=v(\sigma+2 b l)
$$

(Jackson \& Kiørboe 2003) where $b$ is the length of the copepod's antenna and $l$ is the detectable length of the plume. For copepods associated with marine snow aggregates, a representative cruising speed is $V=$ $0.1 \mathrm{~cm} \mathrm{~s}^{-1}$ and a representative antenna length is $b=$ $100 \mu \mathrm{m}$ (e.g. Microsetella spp., Oncaea spp.). Using these parameters, the clearance rate $\beta$ varies from 251 $\mathrm{d}^{-1}$ in perfectly still water, to about $3 \mathrm{l} \mathrm{d}^{-1}$ at turbulence levels $\left(\varepsilon>10^{-6} \mathrm{~m}^{3} \mathrm{~s}^{-2}\right)$ that are associated with the surface mixed layer during strong wind events (Fig. 14). In comparison, clearance calculations based on observed abundances of harpacticoid copepods feeding on aggregates give $8 \mathrm{l} \mathrm{d}^{-1}$ for a $2 \mathrm{~mm}$ aggregate (Kiørboe 2000), corresponding to the theoretical clearance of $\beta=$ $12 \mathrm{l} \mathrm{d}^{-1}$ at reduced levels of turbulence $\varepsilon=10^{-8} \mathrm{~m}^{3} \mathrm{~s}^{2}$ as found for instance in surface layers and the thermocline during low wind speeds. We suggest that the turbulence threshold for triggering an avoidance response of $M$. norwegica was $\varepsilon \sim 10^{7} \mathrm{~m}^{2} \mathrm{~s}^{-3}$ based on the modelled encounter rates (Fig. 14) and observations of avoidance responses and dissipation rates at $z_{C}$ (Figs. 5, 10 \& 11).

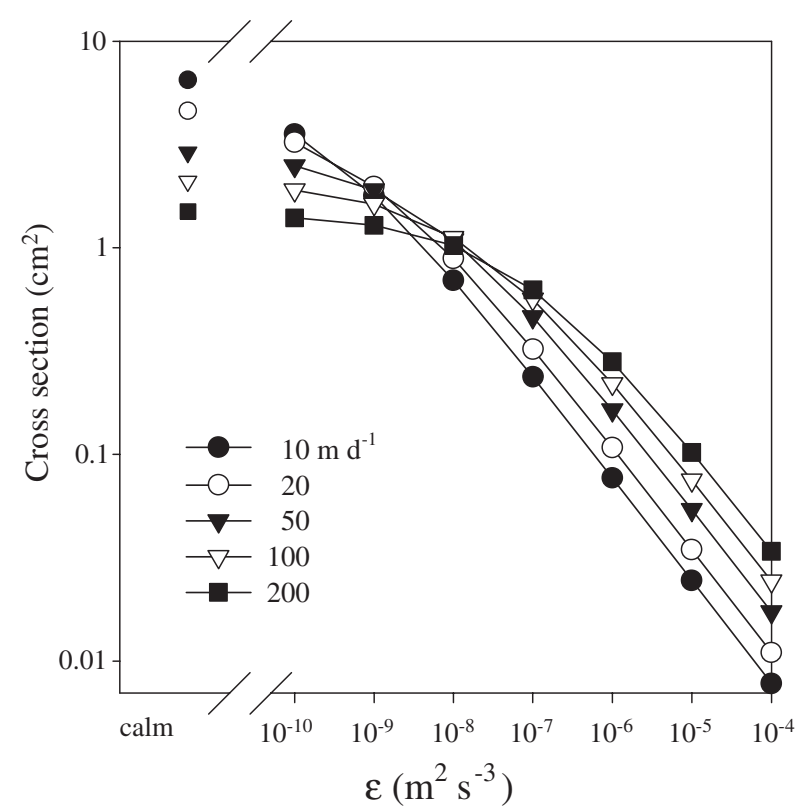

Fig. 13. Cross sectional area of the chemical plume versus turbulent dissipation rate $\varepsilon$ for marine snow aggregates with a fixed particle radius of $0.2 \mathrm{~cm}$ and different sinking velocities $\left(10,20,50,100\right.$ and $\left.200 \mathrm{~m} \mathrm{~d}^{-1}\right)$. The cross sections were calculated according to Visser \& Jackson (2004) assuming a leakage rate of $9 \times 10^{-14} \mathrm{~mol} \mathrm{~s}^{-1}$ and a threshold detection concentration of $3 \times 10^{-8} \mu \mathrm{M}$ (Jackson \& Kiørboe 2003)

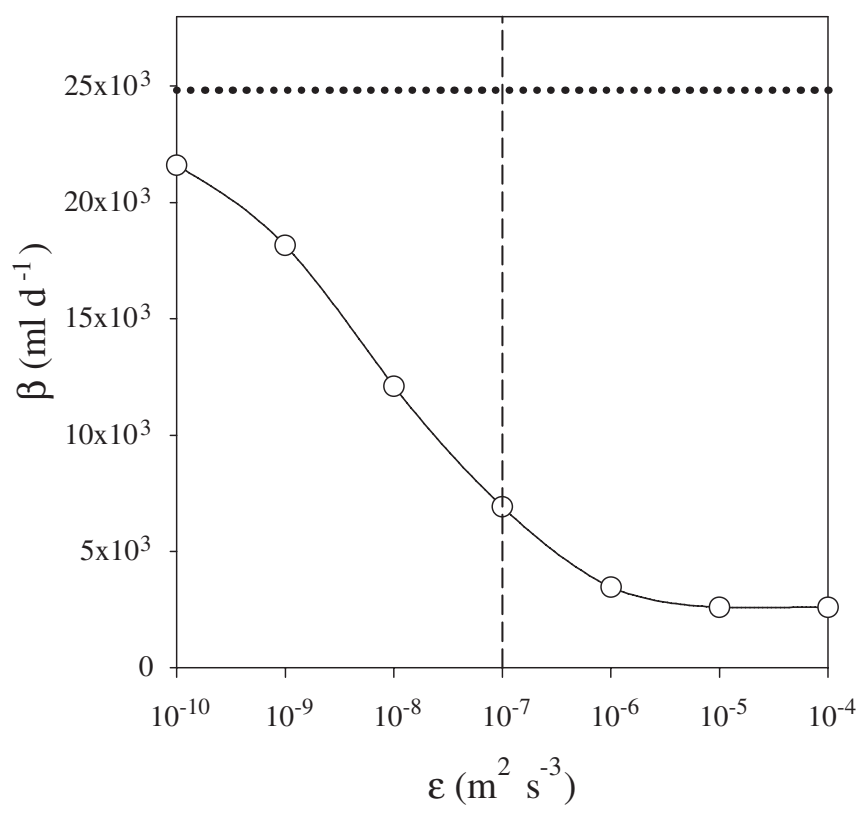

Fig 14. Clearance of a chemosensory, horizontally cruising copepod (antenna length $100 \mu \mathrm{m}$, swimming speed $0.1 \mathrm{~cm} \mathrm{~s}^{-1}$, detection threshold $3 \times 10^{-8} \mu \mathrm{M}$ ) on sinking appendicularian houses (size $2 \mathrm{~mm}$, leaking rate $9 \times 10^{-14} \mathrm{~mol} \mathrm{~s}^{-1}$ ) as a function of turbulent dissipation rate (Eq. 7). The horizontal dotted line indicates clearance rate in perfectly still water, while the vertical dashed line indicates the suggested turbulence threshold for triggering an avoidance response 
In the Skagerrak during summer, discarded appendicularian houses were a possible food source for Microsetella norwegica. Appendicularians are confined to the warm surface layer and their discarded mucus houses are colonised and eaten by a variety of marine organisms including copepods (e.g. Microsetella, Oncaea, Oithona), ciliates, nematodes and bacteria while sinking through the water column. The rate at which discarded houses are colonised and degraded by copepods is dependent on turbulence. The total encounter is 60 houses ind.$^{-1} \mathrm{~d}^{-1}$ at intermediate turbulence levels $\left(\varepsilon \sim 10^{-8} \mathrm{~m}^{2} \mathrm{~s}^{-3}\right)$, when using the encounter kernel of $12 \mathrm{l} \mathrm{d}^{-1}$ and a mean $( \pm \mathrm{SD})$ concentration of discarded houses of $5 \pm 5 \times 10^{3} \mathrm{~m}^{-3}$ during summer in the Skagerrak (M. Maar unpubl. data). However, the average attachment probability was $0.2 \pm 0.2$ for the harpacticoid Amonardia normanni (Koski et al. 2005) and this reduces the encounter followed by attachment (colonization rate) to 12 houses ind. ${ }^{-1} \mathrm{~d}^{-1}$. At strong turbulence levels $\left(\varepsilon \sim 10^{-6} \mathrm{~m}^{2} \mathrm{~s}^{-3}\right)$, the colonization rate is somewhat lower at 4 houses ind..$^{-1} \mathrm{~d}^{-1}$.

The residence time of copepods on aggregates varies from 20 min to several hours (Alldredge 1972, Koski et al. 2005). If we assume a residence time of $1 \mathrm{~h}$ and a carbon intake of $1.0 \mu \mathrm{g} \mathrm{C}$ ind..$^{-1} \mathrm{~d}^{-1}$ at food saturation (Koski et al. 2005), the ingestion was $0.042 \mu \mathrm{g} \mathrm{C}$ ind $^{-1}$ during the colonization time on each house. This corresponds to $3 \%$ of the house carbon assuming $1.5 \mu \mathrm{g} \mathrm{C}$ house $^{-1}$ (Maar et al. 2004). The degradation of houses can then be calculated from the colonization rate, the abundance of $M$. norwegica and the proportion of houses consumed during colonization. For an average concentration of $5000 \mathrm{M}$. norwegica $\mathrm{m}^{-3}$ in the $0-25 \mathrm{~m}$ layer during summer in the Skagerrak (Fig. 6), the degradation is $10 \% \mathrm{~d}^{-1}$ at strong surface turbulence and $34 \% \mathrm{~d}^{-1}$ at intermediate turbulence. Thus, in its first day after being discarded, the appendicularian house is largely untouched by copepodites; however, after its first day, the house will have sunk about $10 \mathrm{~m}$ and come into a region where the degradation due to copepod feeding is 3 to 4 times greater. Thus, it can be supposed that the degradation of appendicularian houses that is mediated by copepodites is largely completed in the 10-30 m layer within $3 \mathrm{~d}$, in agreement with an earlier estimate on the degradation of aggregates based on compiled literature observations (Kiørboe 2000).

\section{CONCLUSIONS}

The present study illustrates the importance of considering behavioural aspects as well as environmental factors in interpreting observed vertical distribution of copepods. This is particularly important in the case of small, but very abundant, understudied copepod genera such as Oithona spp. and Microsetella spp. (Turner 2004). The combination of low turbulence and high food concentrations (microzooplankton, aggregates) below the turbulent surface layer can benefit copepods using hydromechanical or chemodetection feeding strategies. Vertical migration in response to adverse turbulent conditions is likely to be an important behaviour in optimizing the feeding success of these copepods.

Acknowledgements. We are grateful for the technical assistance of K. Tönnesson, P. Tiselius, S. Zervoudaki, E. Christou, B. Søborg, O.S. Hansen, T. Kiørboe, E. Saiz and the crew of the 'Dana'. This study was supported by the KEYCOP-grant (MAST III: MAS3-CT97-0148) and the Danish National Research Council grant \# 9801391 to A.W.V. and T.G.N. We thank B.W. Hansen for detailed comments on the manuscript.

\section{LITERATURE CITED}

Aksnes DL, Giske J (1990) Habitat profitability in pelagic environments. Mar Ecol Prog Ser 64:209-215

Alldredge AL (1972) Abandoned larvacean houses-unique food source in pelagic environment. Science 177:885-887

Alldredge AL, Cowles TJ, MacIntyre S, Rines JEB and 6 others (2002) Occurrence and mechanisms of formation of a dramatic thin layer of marine snow in a shallow Pacific fjord. Mar Ecol Prog Ser 233:1-12

Andersen CM, Nielsen TG (2002) The effect of a sharp pycnocline on plankton dynamics in a freshwater influenced fjord. Ophelia 56:135-160

Båmstedt U (2000) Life cycle, seasonal vertical distribution and feeding of Calanus finmarchicus in Skagerrak coastal water. Mar Biol 137:279-289

Caparroy P, Pérez MT, Carlotti F (1998) Feeding behaviour of Centropages typicus in calm and turbulent conditions. Mar Ecol Prog Ser 168:109-118

Evans GT (1989) The encounter speed of moving predator and prey. J Plankton Res 11:415-417

Fortier L, Leggett WC (1982) Fickian transport and the dispersal of fish larvae in estuaries. Can J Fish Aquat Sci 39: $1150-1163$

Franks PJS (2001) Turbulence avoidance: an alternate explanation of turbulence-enhanced ingestion rates in the field. Limnol Oceanogr 46:959-963

González HE, Smetacek V (1994) The possible role of the cyclopoid copepod Oithona in retarding vertical flux of zooplankton fecal material. Mar Ecol Prog Ser 113: 233-246

Green EP, Dagg MJ (1997) Mesozooplankton associations with medium to large marine snow aggregates in the northern Gulf of Mexico. J Plankton Res 19:435-447

Haury LR, Yamazaki H, Itsweire EC (1990) Effects of turbulent shear on zooplankton distribution. Deep-Sea Res 37 : 447-461

Incze LS, Hebert D, Wolff N, Oakey N, Dye D (2001) Changes in copepod distributions associated with increased turbulence from wind stress. Mar Ecol Prog Ser 213:229-240

Irigoien X, Conway DP, Harris RP (2004) Flexible diel vertical migration behaviour of zooplankton in the Irish Sea. Mar Ecol Prog Ser 267:85-97 
Jackson GA, Kiørboe T (2003) Zooplankton use of chemodetection to find and eat particles. Mar Ecol Prog Ser 269: 153-162

Kiørboe T (2000) Colonization of marine snow aggregates by invertebrate zooplankton: abundance, scaling, and possible role. Limnol Oceanogr 45:479-484

Kiørboe T, Saiz E (1995) Planktivorous feeding in calm and turbulent environments, with emphasis on copepods. Mar Ecol Prog Ser 122:135-145

Kiørboe T, Thygesen UH (2001) Fluid motion and solute distribution around a sinking aggregate. II. Implications for remote detection by colonizing zooplankters. Mar Ecol Prog Ser 211:15-25

Kiørboe T, Visser AW (1999) Predator and prey perception in copepods due to hydromechanical signals. Mar Ecol Prog Ser 179:81-95

Koski M, Kiørboe T, Takahashi K (2005) Benthic life in the pelagial: aggregate encounter and degradation rates by pelagic harpacticoid copepods. Limnol Oceanogr 50(4): $1254-1263$

Lagadeuc Y, Boulé M, Dodson JJ (1997) Effect of vertical mixing on the vertical distribution of copepods in coastal waters. J Plankton Res 19:1183-1204.

Lampert W (1993) Ultimate causes of diel vertical migration of zooplankton: new evidence for the predator-avoidance hypothesis. Ergeb Limnol 39:79-88

Maar M, Nielsen TG, Richardson K, Christaki U and 5 others (2002) Spatial and temporal variability of food web structure during the spring bloom in the Skagerrak. Mar Ecol Prog Ser 239:11-29

Maar M, Nielsen TG, Stips A, Visser AW (2003) Microscale distribution of zooplankton in relation to turbulent diffusion. Limnol Oceanogr 48:1312-1325

Maar M, Nielsen TG, Gooding S, Tönnesson K and 5 others (2004) Trophodynamic function of copepods, appendicularians and protozooplankton in the late summer zooplankton community in the Skagerrak. Mar Biol 144: 917-933

Mackas DL, Sefton H, Miller CB, Raich A (1993) Vertical habitat partitioning by large calanoid copepods in the oceanic sub-Arctic Pacific during spring. Prog Oceanogr 32:259-294

Nielsen TG, Sabatini M (1996) Role of cyclopoid copepods Oithona spp in North Sea plankton communities. Mar Ecol Prog Ser 139:79-93

Ohman MD (1988) Behavioral responses of zooplankton to predation. Bull Mar Sci 43:530-550

Paffenhöfer GA (1983) Vertical zooplankton distribution on the northeastern Florida shelf and its relation to temperature and food abundance. J Plankton Res 5:15-33

Prandke H, Stips A (1998) Test measurements with an operational microstructure-turbulence profiler: detection limit of dissipation rates. Aquat Sci 60:191-209

Reiss CS, Anis A, Taggart CT, Dower JF, Ruddick B (2002) Relationship among vertically structured in situ measures

Editorial responsibility: Otto Kinne (Editor-in-Chief), Oldendorf/Luhe, Germany of turbulence, larval fish abundance and feeding sucess and copepods on Western Bank, Scotian Shelf. Fish Oceanogr 11:156-174

Richardson K, Nielsen TG, Pedersen FB, Heilmann JP, Løkkegaard B, Kaas H (1998) Spatial heterogeneity in the structure of the planktonic food web in the North Sea. Mar Ecol Prog Ser 168:197-211

Rothschild BJ, Osborn TR (1988) Small-scale turbulence and plankton contact rates. J Plankton Res 10:465-474

Saiz E, Kiørboe T (1995) Predatory and suspension feeding of the copepod Acartia tonsa in turbulent environments. Mar Ecol Prog Ser 122:147-158

Saiz E, Alcaraz M, Paffenhöfer GA (1992) Effetcs of smallscale turbulence on feeding rate and gross growth efficiency of 3 Acartia species (Copepoda, Calanoida). J Plankton Res 14:1085-1097

Saiz E, Calbet A, Broglio E (2003) Effects of small-scale turbulence on copepods: the case of Oithona davisae. Limnol Oceanogr 48:1304-1311

Stips A (2005) Dissipation measurements: Theory. In: Baumert H, Simpson JH, Suendermann J (eds) Marine turbulence-theories, observations and methods. Cambridge University Press, Cambridge, p 115-126

Strickland JD, Parsons TR (1972) A practical handbook of seawater analysis. Bull Fish Res Board Can 167

Svensen C, Kiørboe T (2000) Remote prey detection in Oithona similis: hydromechanical versus chemical cues. J Plankton Res 22:1155-1166

Tagushi S (1982) Seasonal study of fecal pellets and discarded houses of appendicularia in a sub-tropical inlet, Kaneohe Bay, Hawaii. Estuar Coast Shelf Sci 14 (5):545-555

Turner JT (2004) The importance of small planktonic copepods and their roles in pelagic marine food webs. Zool Stud 43:255-266

Visser AW (2001) Hydromechanical signals in the plankton. Mar Ecol Prog Ser 222:1-24

Visser AW, MacKenzie BR (1998) Turbulence-induced contact rates of plankton: the question of scale. Mar Ecol Prog Ser 166:307-310

Visser AW, Stips A (2002) Turbulence and zooplankton production: insights from PROVESS. J Sea Res 47:317-329

Visser AW, Jackson GA (2004) Characteristics of the chemical plume behind a sinking particle in a turbulent column. Mar Ecol Prog Ser 283:55-71

Visser AW, Saito H, Saiz E, Kiørboe T (2001) Observations of copepod feeding and vertical distribution under natural turbulent conditions in the North Sea. Mar Biol 138: 1011-1019

Yamazaki H, Squires KD (1996) Comparison of oceanic turbulence and copepod swimming. Mar Ecol Prog Ser 144: 299-301

Yen J, Lenz PH, Gassie DV, Hartline DK (1992) Mechanoreception in marine copepods: electrophysiological studies on the first antennae. J Plankton Res 14:495-512

Submitted: April 13, 2005; Accepted: September 29, 2005

Proofs received from author(s): March 30, 2006 